\title{
PERTUMBUHAN DAN HASIL TANAMAN KUBIS BUNGA (Brassica oleracea L.) AKIBAT PEMBERIAN KOMPOS LIMBAH JAMUR TIRAM DAN PUPUK NPK.
}

\author{
(Plant Growth And Results Cauliflower (Brassica Oleracea L.) Due To The Giving Of Oyster \\ Mushroom Waste Composting And NPK)
}

\author{
Moch. Guntur Purnomo, Muharam, dan Rika Yayu Agustini \\ Program Studi Agroteknologi, Universitas Singaperbansa Karawang \\ Jl. HS.Ronggo Waluyo, Puseurjaya, Kec. Telukjambe Tim., Kabupaten Karawang, \\ Jawa Barat 41361 \\ Penulis Koresponden : Mochguntur7@gmail.com
}

Article Submitted: 25-03-2021

Article Accepted: 29-05-2021

\begin{abstract}
The Cauliflower (Brassica oleracea L.) PM $126 \mathrm{~F} 1$ is one of the vegetable commodities with a high enough demand, because this vegetable is widely consumed by the public. This experiment purposes to get a dose combination of oyster mushroom waste organic fertilizer and NPK fertilizer which gives the highest growth and yield of cauliflower. The method of research used is the experimental method. The design of experimental used was randomize block design (RBD) with a single factor that consisted of 8 treatments with 3 replications, that is : A (control), B (10 ton/ha Organic fertilizer), C (20 ton/ha Organic fertilizer), D (30 ton/ha Organic fertilizer), E (NPK $800 \mathrm{~kg} / \mathrm{ha}), \mathrm{F}$ (10 ton/ha Organic fertilizer + NPK $800 \mathrm{~kg} / \mathrm{ha}), \mathrm{G}$ (20 ton/ha Organic fertilizer + NPK $800 \mathrm{~kg} / \mathrm{ha}), \mathrm{H}$ (30 ton/ha Organic fertilizer + NPK $800 \mathrm{~kg} / \mathrm{ha})$. the result highest curd weight is 7,75 ton/ha achieved by treatment $\mathrm{G}$ is 20 ton / ha waste compost of oyster mushroom and $800 \mathrm{~kg} / \mathrm{ha}$ NPK fertilizer.
\end{abstract}

Keywords: Compost of oyster mushroom waste, cauliflower, NPK fertilizer, organic fertilizer.

\section{PENDAHULUAN}

Tanaman kubis bunga adalah sayuran yang memberikan kontribusi yang besar terhadap kehidupan masyarakat Indonesia sebagai konsumsi gizi. Menjadikan permintaan pasar sayuran ini terus meningkat. Untuk memenuhi permintaan tersebut maka dilakukan peningkatan produksi kubis bunga dapat dengan rekayasa pemupukan yang tepat dosis selama budidaya, seperti pemberian kombinasi pupuk organik dan pupuk anorganik. Pupuk organik adalah pupuk yang sebagian besar atau seluruhnya terdiri atas bahan organik, biasanya yang berasal dari tanaman dan hewan yang telah melalui proses rekayasa, dapat berbentuk padat atau cair yang digunakan untuk mensuplai bahan organik untuk memperbaiki sifat fisik, kimia, dan biologi tanah. Pupuk organik yang sering digunakan adalah pupuk kompos. Pupuk kompos merupakan produk pembusukan dari limbah tanaman dan hewan hasil perombakan oleh fungi, aktinomiset, dan cacing tanah (Suriadikarta dan Simanungkalit 2006). Salah satu pupuk kompos yang dapat digunakan adalah pupuk organik limbah jamur tiram karena di Indonesia masih banyak produksi jamurjamuran.

Pemberian pupuk limbah baglog jamur tiram ditujukan untuk mendukung pertumbuhan dan hasil tanaman. Menurut Bellapama (2015), bahwa pupuk kompos 
limbah baglog jamur tiram memiliki unsur hara $\mathrm{N}, \mathrm{P}$ dan $\mathrm{K}$ yang rendah sehingga dibutuhkan pemberian tambahan pupuk yaitu pupuk NPK, karena dapat memenuhi kebutuhan unsur hara atau nutrisi untuk tanaman. Pemberian kombinasi pupuk organik dengan pupuk anorganik memiliki potensi lebih baik untuk pertumbuhan dan hasil tanaman kubis bunga karena menurut hasil penelitian Fransiska, et. al. (2017) menunjukkan bahwa pemberian pupuk NPK pada tanaman kubis bunga (Brassica oleraceae, L.) memerlukan tambahan pupuk organik untuk mendapatkan pertumbuhan yang lebih baik.

\section{METODE PENELITIAN}

Bahan yang digunakan dalam percobaan adalah benih kubis bunga varietas Botrytis (PM 126 F1), limbah baglog jamur tiram, dedak, gula, EM4, pupuk NPK Mutiara (16:16:16), pestisida dan fungisida. Percobaan dilaksanakan di Kampung Pancur, Desa Bojongleles, Kecamatan Cibadak, Kabupaten Lebak, Provinsi Banten Tipe iklim basah dan jenis tanah sawah dengan ketinggian tanah 272 mdpl. pada bulan Agustus sampai dengan bulan November 2020.

Metode penelitan yang digunakan adalah metode eksperimen Rancangan Acak Kelompok (RAK) faktor tunggal dengan kombinasi perlakuan pupuk kompos limbah baglog jamur tiram dengan dosis pupuk NPK16:16:16, yang terdiri dari 8 perlakuan dan diulang sebanyak 3 kali sehingga terdapat 24 unit percobaan. Perlakuan berikut : A (kontrol), B (kompos 10 ton/ha), C (kompos 20 ton /ha), D (kompos 30 ton /ha), E (NPK $800 \mathrm{~kg} / \mathrm{ha}$ ), F (kompos 10 ton /ha + NPK $800 \mathrm{~kg} / \mathrm{ha}$ ), G (kompos 20 ton /ha + NPK $800 \mathrm{~kg} / \mathrm{ha}$ ), dan H (kompos 30 ton $/ \mathrm{ha}=$ NPK $800 \mathrm{~kg} / \mathrm{ha}$ ). Analisis data diuji lanjut dengan uji jarak berganda duncan atau Duncan Multiple Range Test (DMRT) pada taraf 5\%. Pengamatan dilakukan pada tinggi tanaman $(\mathrm{cm})$, diameter bunga $(\mathrm{cm})$ dan bobot bunga (ton/ha).

\section{HASIL DAN PEMBAHASAN}

\section{Tinggi tanaman (cm)}

Data analisis uji DMRT menunjukkan bahwa pemberian kombinasi dosis kompos limbah baglog jamur tiram dan dosis pupuk NPK memberikan pengaruh nyata terhadap tinggi tanaman saat tanaman berumur 22 hari setelah tanam (hst) sampai 46 hst.

Tabel 1. Rata - rata tinggi tanaman 22 hst, 30 hst, 38 hst, 46 hst pada pemberian kombinasi dosis kompos limbah baglog jamur tiram dan dosis pupuk NPK.

\begin{tabular}{clcccc}
\hline \multirow{2}{*}{ Kode } & \multirow{2}{*}{ Perlakuan } & \multicolumn{3}{c}{ rata-rata tinggi tanaman } \\
\cline { 3 - 5 } & & $22 \mathrm{hst}$ & $30 \mathrm{hst}$ & $38 \mathrm{hst}$ & $46 \mathrm{hst}$ \\
\hline $\mathrm{A}$ & Kontrol & $16,91 \mathrm{~b}$ & $17,95 \mathrm{c}$ & $20,92 \mathrm{c}$ & $24,78 \mathrm{~b}$ \\
$\mathrm{~B}$ & Kompos 10 ton/ha & $16,63 \mathrm{~b}$ & $17,78 \mathrm{c}$ & $20,14 \mathrm{c}$ & $25,18 \mathrm{~b}$ \\
$\mathrm{C}$ & Kompos 20 ton/ha & $18,37 \mathrm{~b}$ & $22,38 \mathrm{bc}$ & $25,38 \mathrm{bc}$ & $28,88 \mathrm{~b}$ \\
$\mathrm{D}$ & Kompos 30 ton/ha & $17,44 \mathrm{~b}$ & $19,35 \mathrm{c}$ & $21,82 \mathrm{c}$ & $26,88 \mathrm{~b}$ \\
$\mathrm{E}$ & NPK 800 kg/ha & $20,62 \mathrm{ab}$ & $27,62 \mathrm{ab}$ & $32,30 \mathrm{ab}$ & $36,94 \mathrm{a}$ \\
$\mathrm{F}$ & 10 ton/ha + NPK 800 kg/ha & $20,37 \mathrm{ab}$ & $28,34 \mathrm{ab}$ & $32,85 \mathrm{ab}$ & $39,00 \mathrm{a}$ \\
$\mathrm{G}$ & 20 ton/ha + NPK 800 kg/ha & $23,79 \mathrm{a}$ & $32,01 \mathrm{a}$ & $34,42 \mathrm{a}$ & $38,05 \mathrm{a}$ \\
$\mathrm{H}$ & $30 \mathrm{ton} / \mathrm{ha}+\mathrm{NPK} \mathrm{800} \mathrm{kg/ha}$ & $18,33 \mathrm{~b}$ & $26,81 \mathrm{ab}$ & $30,56 \mathrm{ab}$ & $37,63 \mathrm{a}$ \\
\hline \multicolumn{2}{c}{$\mathrm{KK} \mathrm{( \% )}$} & 14,40 & 15,02 & 14,94 & 11,51 \\
\hline
\end{tabular}


Pengaruh tinggi tanaman pada pemberian kombinasi dosis kompos limbah baglog jamur tiram dan dosis pupuk NPK relatif cepat. Tinggi tanaman yang diberikan kombinasi dosis kompos limbah baglog jamur tiram dan dosis pupuk NPK berbeda nyata dengan yang hanya diberikan dosis kompos limbah baglog jamur tiram. Hal tersebut diduga karena kadungan nitrogen, phosfor dan kalium kompos limbah baglog jamur tiram relatif rendah sehingga kurang mampu meningkatkan pertumbuhan tinggi tanaman. Menurut Rina D, (2015) bahwa kekurangan unsur hara nitrogen, phosfor dan kalium mengakibatkan tanaman kerdil. Serta kandungan C-organik dari kompos limbah baglog jamur tiram menyebabkan tanah gembur, unsur organik tanah dan kesuburan tanah meningkat yang kemudian ditambahkan unsur hara makro bagi tanaman dari kombinasi pupuk NPK. Keuntungan yang diperoleh dari limbah media tanam jamur ini adalah terjadinya peningkatan unsur organik dalam tanah yang dapat memperbaiki struktur dan kesuburan tanah, unsur organik tersebut diperlukan untuk pertumbuhan tanaman (Yuliastuti dan Adhi, 2003).

\section{Diameter Bunga (cm)}

Berdasarkan tabel 2. menunjukan bahwa pemberian dosis kompos limbah baglog jamur tiram dan pupuk NPK memberikan pengaruh nyata. Diameter bunga tanaman kubis bunga menunjukkan nilai tertinggi pada perlakuan $\mathrm{G}$ yaitu pemberian 20 ton/ha kompos limbah baglog jamur tiram dan pupuk NPK 800 kg/ha. Hal ini diduga karena diameter bunga di pengaruhi oleh unsur hara Nitrogen, Phosfor dan Kalium yang tersedia dari tanah dan dari pemberian pupuk NPK dan dari pemberian kompos limbah baglog jamur tiram, sehingga tanah lebih banyak menyediakan unsur hara tersebut sebagai unsur hara yang akan diserap tanaman. Soepardi (1983) menyatakan, bahwa serapan unsur hara oleh tanaman sangat dipengaruhi oleh kadar dan ketersediaan hara dalam tanah.

Tabel 2. Rata - rata diameter bunga pada pemberian kombinasi dosis kompos limbah baglog jamur tiram dan dosis pupuk NPK.

\begin{tabular}{clc}
\hline \multirow{2}{*}{ Kode } & \multicolumn{1}{c}{ Perlakuan } & rata-rata diameter bunga $(\mathrm{cm})$ \\
\hline $\mathrm{A}$ & Kontrol & $6,18 \mathrm{c}$ \\
$\mathrm{B}$ & Kompos 10 ton/ha & $5,88 \mathrm{c}$ \\
$\mathrm{C}$ & Kompos 20 ton/ha & $8,76 \mathrm{~b}$ \\
$\mathrm{D}$ & Kompos 30 ton/ha & $5,53 \mathrm{c}$ \\
$\mathrm{E}$ & NPK 800 kg/ha & $10,28 \mathrm{ab}$ \\
$\mathrm{F}$ & $10 \mathrm{ton} / \mathrm{ha}+\mathrm{NPK} \mathrm{800} \mathrm{kg/ha}$ & $11,10 \mathrm{ab}$ \\
$\mathrm{G}$ & $20 \mathrm{ton} / \mathrm{ha}+\mathrm{NPK} \mathrm{800} \mathrm{kg/ha}$ & $12,16 \mathrm{a}$ \\
$\mathrm{H}$ & 30 ton/ha + NPK 800 kg/ha & $9,60 \mathrm{~b}$ \\
\hline \multicolumn{2}{c}{ KK $(\%)$} & 14,79 \\
\hline
\end{tabular}

Menurut Kurniawan dan Widaryanto (2019) bahwa penambahan limbah media tanam jamur tiram dapat menurunkan hasil hingga $40 \%$. Berdasarkan tabel di atas perlakuan $\mathrm{G}$ berbeda nyata pada perlakuan H. Hal ini menunjukan bahwa pemberian dosis 30 ton/ha kompos baglog limbah jamur tiram dan dosis pupuk NPK malah menurunkan nilai diameter bunga walaupun pemberian dosis kompos limbah baglog jamur tiram ditambahkan. Sehingga pemberian dosis kompos limbah jamur tiram lebih dari 30 ton/ha dianggap dapat menekan pertumbuhan diameter batang akan tetapi tidak pada dosis 20 ton/ha kompos limbah jamur 
tiram dan pupuk NPK yang mana memberika hasil tertinggi pada diameter bunga.

\section{Bobot Bunga (ton/ha)}

Data hasil uji DMRT taraf 5\% menunjukkan bahwa kombinasi dosis kompos limbah baglog jamur tiram dan dosis pupuk NPK memberikan pengaruh yang nyata terhadap bobot bunga dengan hasil tertinggi didapatkan dari perlakuan $\mathrm{G}$ (pupuk kompos limbah baglog jamur tiram 20 ton/ha dan pupuk NPK $800 \mathrm{~kg} / \mathrm{ha}$ ). Akan tetapi perlakuan $\mathrm{G}$ berbeda nyata dengan perlakuan lain. Hal tersebut membuktikan bahwa terdapat dosis terbaik pada bobot bunga. Menurut Setyamidjaja (2006) bahwa untuk mendapatkan hasil yang optimal, pemupukan harus diberikan dalam jumlah yang mencukupi kebutuhan tanaman yaitu tidak berlebihan dan tidak kekurangan, pemberian pupuk dalam jumlah yang tepat akan diperoleh hasil yang optimal.

Tabel 3. Rata - rata bobot bunga pada pemberian kombinasi dosis kompos limbah baglog jamur tiram dan dosis pupuk NPK.

\begin{tabular}{|c|c|c|c|}
\hline \multirow{2}{*}{ Kode } & \multirow{2}{*}{ Perlakuan } & \multicolumn{2}{|c|}{ rata-rata bobot bunga per petak } \\
\hline & & (kg/petak) & (ton/ha) \\
\hline A & Kontrol & $2,02 \mathrm{~b}$ & $3,37 \mathrm{~b}$ \\
\hline $\mathrm{B}$ & Kompos 10 ton/ha & $1,77 \mathrm{~b}$ & $2,95 \mathrm{~b}$ \\
\hline $\mathrm{C}$ & Kompos 20 ton/ha & $2,44 \mathrm{~b}$ & $4,07 \mathrm{~b}$ \\
\hline $\mathrm{D}$ & Kompos 30 ton/ha & $1,65 \mathrm{~b}$ & $2,74 \mathrm{~b}$ \\
\hline $\mathrm{E}$ & NPK $800 \mathrm{~kg} / \mathrm{ha}$ & $4,18 \mathrm{a}$ & $6,97 \mathrm{a}$ \\
\hline $\mathrm{F}$ & 10 ton $/ \mathrm{ha}+\mathrm{NPK} 800 \mathrm{~kg} / \mathrm{ha}$ & $4,40 \mathrm{a}$ & $7,33 \mathrm{a}$ \\
\hline $\mathrm{G}$ & 20 ton $/ \mathrm{ha}+\mathrm{NPK} 800 \mathrm{~kg} / \mathrm{ha}$ & $4,65 \mathrm{a}$ & $7,75 \mathrm{a}$ \\
\hline $\mathrm{H}$ & 30 ton $/ \mathrm{ha}+$ NPK $800 \mathrm{~kg} / \mathrm{ha}$ & $4,54 \mathrm{a}$ & $7,57 \mathrm{a}$ \\
\hline
\end{tabular}

Pemberian dosis kompos limbah baglog jamur tiram 20 ton/ha dan dosis pupuk NPK $800 \mathrm{~kg} / \mathrm{ha}$ memberikan hasil terbaik pada bobot bunga. Hal tersebut diduga karena pada dosis perlakuan $\mathrm{G}$ tanaman sudah dapat menyerap unsur hara yang dapat mempengaruhi bobot bunga seperti pada kandungan unsur hara $\mathrm{P}$ dimana berfungsi sebagai pemacu pembentukan bunga yang kemudian dan didukung oleh unsur hara lain nya. Kandungan phosfor dapat memacu pembentukan bunga sehingga mempercepat masa panen (Rina D, 2015).

Menurut Imam dan Widyastuti (1992) menyatakan bahwa tinggi rendahnya bobot bunga tanaman tergantung pada banyak atau sedikitnya serapan unsur hara yang berlangsung selama proses pertumbuhan tanaman. Nyakpa, et al. (1988) menyatakan bahwa ketersediaan unsur hara nitrogen, phosfor, dan kalium yang optimal bagi tanaman dapat meningkatkan jumlah klorofil, peningkatan klorofil akan meningkatkan aktifitas fotosintesis yang menghasilkan asimilat lebih banyak yang mendukung bobot bunga tanaman.

Berdasarkan tabel 3. bahwa perlakuan $\mathrm{G}$ memeberikan hasil tertinggi pada bobot bunga per petak kemudian di konversi ton per hektar yaitu seberat 7,75 ton/ha, akan tetapi bobot bunga tersebut belum memenuhi atau tidak sesuai deskripsi benih kubis bunga PM 126 F1 yaitu $18-20$ ton/ha.

\section{KESIMPULAN}

Terdapat pengaruh yang nyata pada pemberian kombinasi dosis kompos limbah baglog jamur tiram dan pupuk NPK terhadap pertumbuhan dan hasil tanaman 
kubis bunga (Brassica oleracea L.) PM 126 F1. Pengaruh nyata ini diperlihatkan terhadap seluruh variabel respon. Serta pemberian kompos limbah baglog jamur tiram pada dosis 20 ton/ha dan pupuk NPK pada dosis $800 \mathrm{~kg} / \mathrm{ha}$ menunjukan hasil terbaik untuk pertumbuhan dan hasil tanaman kubis bunga (Brassica oleracea L.) PM 126 F1.

\section{UCAPAN TERIMA KASIH}

Penulis pertama mengucapkan terima kasih kepada Fakultas Pertanian Universitas Singaperbangsa Karawang atas dukungan pelaksanaan penelitian. Kemudian terima kasih kepada Badan Meteorologi Klimatologi dan Geofisika Stasiun Klimatologi Tangerang Selatan dan ICBB Laboratorium Bioteknologi Lingkungan PT Biodiversitas Bioteknologi Indonesia atas dukungan data - data pada penelitian. Terakhir terima kasih kepada bapak Hj. Edi Purnomo S. Km., M. Kes., M. M., atas dana dari awal sampai akhir pelaksanaan penelitian.

\section{DAFTAR PUSTAKA}

Bellapama, I. A., K. Hendarto dan Widyastuti, R. A. D. (2015). Pengaruh Pemupukan Organik Limbah Baglog Jamur Dan Pemupukan Takaran Npk Terhadap Pertumbuhan Dan Produksi Pakchoy (Brassica chinensis L). J. Agrotek Tropika. ISSN 2337-4993 Vol. 3, No. 3: $327-331$.

Fransiska, G. D., Sulistyawati dan Pratiwi, S. H. (2017). Respon Pemberian Pupuk Organik Dan An Organik Terhadap Pertumbuhan Dan Hasil Tanaman Kubis Bunga (Brassica oleraceae, L.) Dataran Rendah. Jurnal Agroteknologi Merdeka Pasuruan. Volume 1. Nomor 2. Hal. 1-10.
Imam, S. dan Widyastuti, Y. E. (1992). Kelapa Sawit. Penebar Swadaya. Jakarta.

Nyakpa. (1988). Kesuburan Tanah. Universitas Lampung. Lampung.

Rina D. 2015. Manfaat Unsur N, P, dan $K$ Bagi Tanaman. Balai Pengkajian Teknologi Pertanian Kalimantan Timur. Retrieved from http://kaltim.litbang.pertanian.go.id/i nd/index.php?option=com_content\& view $=$ article $\& i d=707 \&$ Itemid $=59$.

Setyamidjaja, D. 2006. Budidaya Kelapa Sawit. Kanisius. Yogyakarta.

Soepardi, G. 1983. Sifat dan Ciri Tanah. Pustaka Buana. Bandung.

Suriadikarta, D. A. dan Simanungkalit, R. D. M. (2006). Pupuk Organik dan Pupuk Hayati. Bogor (ID): Balai Besar Litbang Sumberdaya Lahan Pertanian Badan Penelitian dan Pengembangan Pertanian.

Yuliastuti dan Adhi, S. (2003). Studi Kandungan Nutrisi Limbah Media Tanam Jamur Tiram Putih Untuk Pakan Ternak. Retrieved from http://Eko_Yuliastuti_ES_Studi Kandungan Nutrisi Limbah Media Tanam. 